\title{
¿Descargo de conciencia o limpieza del pasado? Un estudio sobre la autobiografía de Pedro Laín Entralgo
}

\author{
Manuela Sánchez García \\ Universidad de Córdoba
}

Título: ¿Descargo de conciencia o limpieza del pasado? Un estudio sobre la autobiografía de Pedro Laín Entralgo.

Resumen: Pedro Laín Entralgo publicó su autobiografía Descargo de conciencia en abril de 1976. Este trabajo, que aplica la concepción de la autobiografía de Loureiro como un acto a la vez discursivo, intertextual, retórico, ético y político, se propone demostrar que, además de descargar la conciencia, Laín Entralgo pretendió justificar su pasado, limpiarlo y hacerlo presentable para seguir siendo una figura intelectual y política en la transición a la democracia que entonces comenzaba. Para ello utilizó unas estrategias retóricas precisas que dejan todo organizado ante el lector. Por otro lado, la ambigüedad de la obra ha dado lugar a dos lecturas diferentes: la del momento de la publicación y la que se hace desde el cambio de milenio hasta la actualidad (Isaac Rosa, Gregorio Morán...).

Palabras clave: Laín Entralgo, Autobiografía, Testimonio, Confesión, Culpa.

Fecha de recepción: 28/10/2015.

Fecha de aceptación: 8/11/2015.
Title: The Ease of a Guilty Conscience or a Cleaning of the Past? A Study of Laín Entralgo's Autobiography.

Abstract: Pedro Laín Entralgo published his autobiography Descargo de conciencia in April of 1976. This article, that applies Loureiro's autobiographical conception as an act at once discursive, intertextual, rhetorical, ethical and political, aims to demonstrate that, in addition to easing his conscience, Laín Entralgo tried to justify his past, clean it and make it presentable in order to continue being an intellectual and political figure in the Transition to democracy that was beginning then. For that purpose, he used accurate rhetorical strategies to present everything organized for the reader. On the other hand, the ambiguity of the book has involved two different readings: the one at the publication time and a second one from the turning of the millennium until now (Isaac Rosa, Gregorio Morán...).

Key words: Laín Entralgo, Autobiography, Testimony, Confession, Guilt.

Date of Receipt: 28/10/2015.

Date of Approval: 8/11/2015. 


\section{Descargo de conciencia de Pedro Laín Entralgo}

Pedro Laín Entralgo (1908-2001) fue una figura destacada de la intelectualidad española durante los años del franquismo. Su labor como historiador de la medicina, pensador y analista de la cultura aparece reflejada en una amplia bibliografía: Medicina e historia (1941), Historia de la medicina (1954), España como problema (1956), La relación médico-enfermo (1964), A qué llamamos España (1971), Sobre la amistad (1972)... Laín aprovecha un contexto histórico de gran incertidumbre (acaba de morir Franco y la incipiente transición, con la monarquía ya instaurada, avanza lentamente hacia la democracia) para publicar Descargo de conciencia ${ }^{1}$, que apareció en abril de 1976, cuando tenía sesenta y ocho años. En todas las ediciones junto al título aparecen entre paréntesis dos fechas (19301960) que abarcan los casi treinta años que transcurren entre la llegada del autor a Madrid para encauzar su carrera profesional en el mundo de la Medicina y su destitución como rector de la Universidad de esa misma ciudad en 1956. A estos años están dedicados los siete capítulos en los que se divide el libro: I. Madrid cambiante; II. No sólo psiquiatra; III. Guerra civil: de Santander a Pamplona; IV. Guerra civil: Navarra y otras tierras; V. Guerra civil: de Burgos a Madrid; VI. Otro Madrid, otros caminos; VII. Rector, ma non troppo. Este gran núcleo central va precedido de una "Introducción" en la que narra brevemente sus primeros treinta años de vida (infancia y estudios de Bachillerato y Universidad) y seguido de un "Epílogo" en el que cuenta lo que ha sido su vida desde la salida del Rectorado hasta el momento de la escritura (1975). Tanto una como otro sintetizan los años irrelevantes para la intención principal de la obra. Los siete capítulos, la Introducción y el Epílogo terminan con lo que Laín ha denominado epicrisis, quizás la originalidad más notoria de esta autobiografía y de las que se hablará más adelante.

Para el análisis de Descargo de conciencia se ha aplicado la teoría autobiográfica de Loureiro, expuesta en su libro The Ethics of Autobiograhy ${ }^{2}$.

1 Pedro Laín Entralgo, Descargo de conciencia, Barcelona, Galaxia Gutenberg, 2003. Todas las citas pertenecen a esta edición.

2 Ángel Loureiro, The Ethics of Autobiography. Replacing the Subject in Modern Spain, 
Hasta la aparición de este libro en 2000, la crítica autobiográfica se dividía en dos corrientes perfectamente explicadas por Pozuelo Yvancos ${ }^{3}$. La primera sería la conocida como deconstrucción, que se coloca en la perspectiva retórica desde la que se defiende la ficcionalidad del sujeto autobiográfico, que se construye en el momento de la escritura, ya que la autobiografía crea una identidad que no es previa al discurso. Esta corriente parte de Nietzsche y es defendida por De Man, Derrida y Roland Barthes. La segunda, que respaldan Lejeune y Bruss entre otros, estudiaría la autobiografía desde el punto de vista pragmático y entiende que, siendo inevitable en la autobiografía, como en cualquier narración, una elaboración de la realidad, lo que verdaderamente la caracteriza es su promesa de veracidad, de manera que la identificación mediante el pacto de lectura del yo textual con el yo que escribe obliga a que se presenten como reales los hechos que se narran y que estos puedan ser sometidos a una prueba de verificación histórica. Pozuelo Yvancos, que habla de la dimensión fronteriza ${ }^{4}$ de este tipo de textos, propone aunar estas dos posturas aparentemente contrapuestas mediante la consideración de la autobiografía como un discurso ficcional desde el punto de vista semántico y ontológico y como un discurso de verdad pragmáticamente considerado 5 .

Sin embargo, para abordar el estudio de una obra como Descargo de conciencia ni las dos posturas críticas anteriores ni la superación que intenta Pozuelo Yvancos son suficientes. Es evidente que una autobiografía no es una reproducción de una vida, sino una elaboración de la misma orientada en y para el presente. No obstante, la construcción retórica de un yo y/o la modificación creativa de una vida no están reñidas con la preocupación ética del autor de dirigirse a los otros, por eso es precisamente el planteamiento crítico que presenta Loureiro el que se convierte en indispensable en un trabajo como este, pues considera la autobiografía

Nashville, Vanderbilt University Press, 2000.

3 José María Pozuelo Yvancos, De la autobiografía. Teoría y estilos, Barcelona, Editorial Crítica, 2005, p. 24.

4 Ibidem, p. 15.

5 Ibidem, p. 45. Por otro lado, este debate teórico, que se explica por la imposibilidad de un estatuto específico de lo autobiográfico, penetró en los propios textos, como en La escritura o la vida de Jorge Semprún, La costumbre de vivir y en menor medida Tiempo de guerras perdidas de Caballero Bonald, Recuerdos y olvidos de Francisco Ayala, Corre, Rocker de Sabino Méndez... 
como un discurso complejo que debe abordarse desde distintos planos. Afirma Loureiro ${ }^{6}$ que las críticas que había hecho De Man a las ilusiones cognoscitivas de la autobiografía parecían prácticamente insuperables. Sin embargo, el descubrimiento de la filosofía de Levinas le ayudó a enfocar el estudio crítico de la autobiografía desde el punto de vista ético, perspectiva que supondría salir del atolladero en el que se encontraban las discusiones entre las dos corrientes críticas arriba indicadas. La responsabilidad ética tiene, según Levinas ${ }^{7}$, dos significados básicos. En primer lugar, significa que el sujeto se constituye como una respuesta a la llamada del otro, y, en segundo lugar, que esa responsabilidad implica que uno no puede permanecer inmóvil ante la petición del otro: la compasión, la generosidad o la solidaridad serían algunas de las manifestaciones de la ineludible necesidad de responder al sufrimiento de los otros. Esta responsabilidad no se origina en ningún pacto pragmático o social, defiende Levinas, sino que es anterior a cualquier acuerdo legal o moral y obliga al sujeto más allá de esos convenios. Por tanto, concluye Loureiro ${ }^{8}$, las dimensiones discursivas, retóricas y éticas de la autobiografía están inextricablemente unidas y para acercarnos a ella de una manera global, sin las limitaciones de las aproximaciones referenciales o epistemológicocognitivas, hay que complementar estas con lo ético, que se manifiesta en una variedad de actos performativos y de formas de discurso inherentes al género. Comprenderemos mejor la autobiografía si la consideramos, no como una reproducción de una vida, sino como un acto que es a la vez discursivo, intertextual, retórico, ético y político 9 . Este es exactamente el enfoque que adopta el presente estudio.

\section{TESTIMONIO Y/O CONFESIÓN}

En Descargo de conciencia el testimonio se conjuga con la intención confesional, poniéndose aquel al servicio de esta. En el ámbito jurídico, la palabra testimonio designa un tipo de prueba que acredita la existencia

\footnotetext{
6 Ángel Loureiro, op. cit., p. IX.

7 Ibidem, pp. XII-XIII.

8 Ibidem, p. IX.

9 Ibidem, p. 4.
} 
y veracidad de los hechos que se presentan en un proceso con el fin de convencer al juez de la verdad o falsedad de los hechos alegados. El testigo es la persona física que sin ser parte en un proceso comparece ante el órgano jurisdiccional a prestar declaración contestando a las preguntas que el Juez le formule sobre lo que considere de trascendencia en el proceso. Es sustancial la aclaración "sin ser parte en un proceso", pues si los que atestiguan fueron parte de los hechos, la figura jurídica deja de ser la del testimonio para pasar a la confesión, que es el medio de prueba en el que una de las partes declara ante el juez.

Si consideramos el testimonio en el ámbito autobiográfico, el acto ético del que hablaba Loureiro se manifiesta en que los autobiógrafos testimoniales consideran como una de sus finalidades esenciales la de relatar lo vivido para que los otros conozcan unas experiencias de las que ellos se consideran, por distintas razones, protagonistas o testigos privilegiados. Esta finalidad es esencial en las obras que relatan las vivencias traumáticas que han experimentado los supervivientes de una guerra o de los campos de concentración y exterminio nazis, $y$, así, el afán por preservar del olvido los hechos trágicos de los que han sido testigos es el leitmotiv de alguno de los textos autobiográficos más importantes sobre los campos de concentración, como los de Primo Levi, Jorge Semprún o Kertész. Primo Levi lo expresa de este modo:

Por ello, este libro mío, por lo que se refiere a detalles atroces, no añade nada a lo ya sabido por los lectores de todo el mundo sobre el inquietante asunto de los campos de destrucción. No lo he escrito con intención de formular nuevos cargos; sino más bien de proporcionar documentación para un estudio sereno de los aspectos del alma humana. [...] La necesidad de hablar a "los demás", de hacer que "los demás" supiesen, había asumido entre nosotros, antes de nuestra liberación y después de ella, el carácter de un impulso inmediato y violento, hasta el punto de que rivalizaba con nuestras demás necesidades más elementales; este libro lo escribi para satisfacer esta necesidad ${ }^{10}$.

El hecho de haber sobrevivido y de haber vuelto indemne se debe, en mi opinión, a que tuve suerte. [...] Quizás también me haya ayudado mi interés, que nunca flaqueó, por el ánimo humano y la vo-

10 Primo Levi, Los hundidos y los salvados, Barcelona, Muchnik Editores, 1995, pp. 9-10. 
luntad no sólo de sobrevivir (común a todos) sino de sobrevivir con el fin preciso de relatar las cosas a las que habiamos asistido y que habiamos soportado ${ }^{11}$.

Además de este esencial compromiso ético de contar los hechos de los que se ha sido testigo para que no se olviden y para que no vuelvan a repetirse, las autobiografías testimoniales deben presentar otros tres aspectos. En primer lugar, la capacidad cognitiva, la vertiente intelectual del narrador que, antes de relatar sus vivencias, tiene que comprenderlas. En segundo lugar, la buena (o mala) memoria del testigo, que da a lugar a retóricas autobiográficas distintas, que irán desde las se apoyan en una seguridad indudable en la capacidad memorística del autobiógrafo hasta las que manifiestan una continua desconfianza en dicha capacidad. Por último, un compromiso moral de veracidad por parte del testigo, que se asienta, además de en la retórica textual, en los elementos paratextuales que se ańaden, como pueden ser los documentos, las fotografías, los recortes de prensa...; en definitiva, todo lo que ayude a corroborar la veracidad de lo que se narra.

Al igual que en el espacio judicial, en las obras autobiográficas hay que distinguir entre testimonio y confesión, de manera que el valor testimonial de algunas autobiografías, por ejemplo las de Dionisio Ridruejo o Laín Entralgo, no es el mismo que el de otros autores, pues aquellos fueron parte de los hechos que relatan y, por tanto, sus obras tendrán un sentido más confesional que testimonial. Descargo de conciencia pertenecería, por tanto, a la tradición confesional iniciada por San Agustín y continuada por Rousseau.

El aparente propósito esencial de la autobiografía de Laín Entralgo es el que el título expresa: el descargo de conciencia. Ahora bien, como en muchas autobiografías, las palabras del prólogo son fundamentales para entender el propósito de Laín Entralgo al escribir la suya. En primer lugar menciona Laín dos finalidades para el libro: la primera, "una exploración memorativa de mi propia realidad" y la segunda, "un testimonio crítico de lo que durante los treinta años más centrales de mi vida han sido ante mi y dentro de mi la historia y la sociedad de España", pero añade una pregunta imprescindible en la intención final de la obra: “¿Ajuste de cuentas con-

11 Ibidem, p. 211. 
migo mismo?”12. Con esta pregunta y su respuesta (“Tal vez”), el autor deja entrever la finalidad principal de la obra que él intenta diluir en lo que denomina "otros fines": 1. una defensa del ejercicio de la palinodia; 2. la narración de la experiencia de sí mismo y de su circunstancia como persona inclinada a ver con claridad y entender con precisión lo que le sucede a él mismo y a su entorno; y 3. un relato predominantemente intelectual de su vida, en el que se integre a la vez la reflexión antropológica. Termina el prólogo con una fórmula clásica de captatio benevolentiae, recomendada por Aristóteles ${ }^{13}$ para "retirar obstáculos", con la que Laín Entralgo desea que el libro sea juzgado a la vez como confesión y consejo "por quienes con buena voluntad lleguen a leerlo" ${ }^{14}$. Aparece, de este modo, el primer intento de desactivación de los posibles prejuicios con los que él cree que el lector se enfrenta a su autobiografía. No hay que olvidar el contexto de su publicación ni que Laín ha sido una destacada figura política e intelectual del régimen franquista, por lo que el receptor del libro espera encontrar en él la explicación a sus adscripciones.

Asimismo, el sugerente título se relaciona con el primer momento del sacramento de la confesión católica, el examen de conciencia, aplicado además a un hombre para el que la religión constituye uno de sus pilares vitales. Sin embargo, el examen ha sufrido una significativa transformación en descargo. La sustitución es deliberada pues esta última palabra presenta unas connotaciones esenciales en la(s) finalidad(es) de esta autobiografía. Por un lado, con su significación jurídica, anticipa la dramatización judicial a la que es sometida la confesión, que quedará evidenciada en las epicrisis finales de cada capítulo. Por otro, descargo posee las acepciones de explicación, justificación e, incluso, de liberación o satisfacción ${ }^{15}$ que no tiene la palabra "examen", términos unidos inevitablemente a la mala conciencia.

Pedro Laín Entralgo manifiesta en varias ocasiones que tuvo un problema de conciencia (el segundo momento de la confesión católica: el

12 Pedro Laín Entralgo, op. cit., p. 25.

13 Aristóteles, Retórica, Madrid, Instituto de Estudios Políticos, 1971, p. 214.

14 Pedro Laín Entralgo, op. cit., p.26.

15 El libro termina con estas palabras: "Confesando mi conciencia, la he descargado. Me siento más humilde y más ligero. Humildemente, pues, diré ante el mañana incierto y transitable: "Aún... Aún..." (Ibidem, p. 469) 
dolor de los pecados o la contrición), o lo que es lo mismo, un sentimiento de culpa. Aprovecha diferentes contextos, capítulos y epicrisis para manifestarlo con mayor o menor explicitud: "pero más aún que calidad en mi obra, lo que yo quiero en este momento, te lo juro, es mayor paz dentro de mi conciencia"16; "Seis, siete lustros más tarde, desde mi personal insignificancia, desde el seno de mi mala conciencia por omisión..." ${ }^{17}$. Bastante más rotundo se muestra cuando expresa su pesadumbre por su adhesión al régimen nazi: "Aunque todavía me queme el alma, y acaso precisamente porque todavía me la quema tanto, no puedo echarte en cara tu ocasional afección a la Alemania nacionalsocialista. Con dolor me arrepiento de ella" ${ }^{18}$. No obstante es en las últimas páginas del libro, al transcribir una carta escrita, según él, en 1963, pero finalmente no enviada, cuando aparecen las declaraciones más explícitas de su mala conciencia: "Un problema de conciencia que siempre mal resuelto llevo dentro de mí desde hace muchos años" 19 , "tal es la raíz del personal problema de conciencia que malamente trató de resolver en mi alma la firma de un documento..." 20 . Y para el final, la confesión más desgarradora de su conflicto: "Por todo ello, mi conciencia moral ha vivido intimamente perturbada desde aquel agosto de 1936 hasta hoy mismo" 21.

Las causas del problema de conciencia que empuja a Laín a la confesión son también expuestas en la obra. En varias ocasiones se refiere a arrepentimientos y errores concretos, por ejemplo, de algo de lo que escribió en Escorial2 ${ }^{2}$. No se observa, no obstante, demasiado arrepentimiento en relación a dos hechos innegables que no podía dejar de tratar en la palinodia en la que quiere convertir Descargo de conciencia: el primero es el de la publicación del "librito" Los valores morales del Nacionalsindicalismo, y el segundo sus adhesiones a la Alemania y la Italia fascistas. En el primer caso se extiende en una reflexión sobre las clases de arrepentimientos (por vergüenza, por error y por deficiencia) para llegar a la conclusión de que

16 Ibidem, p. 151.

17 Ibídem, p. 267.

18 Ibidem, p. 351.

19 Ibidem, p. 422.

20 Ibidem, p. 424.

21 Ibidem, p. 425.

22 Ibidem, p. 271. 
los suyos corresponden solamente a los dos últimos; por cierto, los menos culposos, porque no trasgreden los principios éticos ${ }^{23}$. Del segundo hecho afirma: "error grave, sí, y hoy para mí bien ingrato, pero -así me atrevo a creerlo- no culposo" ${ }^{24}$. Además, también lleva sobre su conciencia todas las cuestiones que se plantea en la nota 6 del capítulo VI, alguna de ellas tan importante como la obligación de la Iglesia de preguntarse por las causas de la violencia contra ella por parte del pueblo o la incapacidad de la derecha española de hacer públicas las atrocidades cometidas durante la guerra ${ }^{25}$. No obstante, es su silencio ante los crímenes cometidos por el franquismo lo que le causa mayor pesadumbre y así lo reconoce cuando, al hablar ya en el epílogo del pecado histórico" ${ }^{26}$ confiesa: "Éste, éste es precisamente el nervio de mi problema de conciencia" 27.

Sin embargo, la contrición de Laín podía haber dado lugar a una confesión privada. ¿Por qué la hace pública? En primer lugar, porque la palinodia, de la que él se autodenomina "virtuoso" 28 , requiere esa publicidad. En segundo, porque como el propio Laín ${ }^{29}$ argumenta, la revisión de una vida tiene que ser pública si la actividad personal puede influir en las opiniones o decisiones de los otros, como ocurre con los políticos o los intelectuales, de manera que el cambio de las ideas o de las creencias exige la explicación pública de las razones de ese cambio. En Descargo de conciencia, sostiene que ante un pecado histórico lo que debe hacerse es "denunciarlo públicamente, pronunciar desde la propia conciencia perso-

23 Ibidem, p. 265.

24 Ibidem, p. 295.

25 Ibidem, p. 267.

26 Se refiere con este término a la falta de reconocimiento público por parte del bando nacional de los crímenes perpetrados durante la guerra y la posterior represión, sobre todo en los que han ocupado puestos ejecutivos o rectores en la vida pública.

27 Ibidem, p. 426.

28 Hace alusión a esta expresión en numerosas ocasiones: "yo pertenezco a una rara variedad de sus habitantes, la de los virtuosos de la palinodia" (p. 139, nota 8); "virtuoso de la palinodia" [...] me he llamado con frecuencia" (p. 192); "aunque uno se llame a sí mismo virtuoso de la palinodia" (p. 350); "soy, ya lo he dicho, un virtuoso de la palinodia, más aún, un predicador de ella” (p. 416).

29 Pedro Laín Entralgo, Hacia la recta final (Revisión de una vida intelectual), Barcelona, Círculo de Lectores, 1990, p. 22. 
nal un nostra culpa hondo y sincero" ${ }^{30}$, pues los pecados personales exigen confesión privada y los históricos confesión pública.

No obstante, al lector avisado se le ocurren otras razones para haber publicado esta palinodia, sobre todo en el contexto socio-político en el que apareció. Recordemos que confiesa que su perturbación moral nació en agosto de 1936, por lo que tarda cuarenta años en revelar esta zozobra. Él mismo sabe que es uno de los reproches que pueden hacérsele y en la epicrisis del capítulo VI pone en palabras del juez la objeción de "no haber hecho antes el descargo de conciencia que ahora haces". La respuesta de Laín al juez, en forma de interrogación retórica, no deja lugar a dudas: “¿Por qué había de apresurarme en la confección de confesiones públicas [...] si yo no me sentía moralmente culpable?"31. Aquí aparece la contradicción más importante de la obra: si no se sentía moralmente culpable, ¿por qué habla de doloroso arrepentimiento al referirse a su afección a la Alemania nazi, o por qué escribió esa carta en 1963 que le salió "de lo hondo del alma” y en la que expresa que su "conciencia moral ha vivido íntimamente perturbada desde aquel agosto de 1936 hasta hoy mismo?”. ¿A qué Laín hemos de creer, al que dice que no hizo antes el descargo de conciencia porque no se sentía moralmente culpable o al que confiesa con desgarro un remordimiento íntimo que ha durado cuarenta años?

Se sintiera o no moralmente culpable, viviera o no en un estado de íntima perturbación, lo que es un hecho irrefutable es que esperó a la muerte de Franco para publicar su descargo, puede que para evitar posibles problemas con la censura y porque, al fin y al cabo, él nunca había roto de forma abierta sus relaciones con el régimen franquista, como sí hicieron algunos de sus amigos. Pero también se puede pensar, si nos atenemos a la información de su biógrafo Diego Gracia ${ }^{32}$, que Laín, a la altura de 1971, cuando publica $A$ qué llamamos España, ya ve aproximarse cambios políticos y administrativos a los que quiere adaptarse haciendo presentable su pasado, pues desea jugar también un papel importante en la transición a la democracia. De esta forma, justificando, limpiando lo que hay de

30 Descargo de conciencia, p. 426.

31 Ibidem, p. 350.

32 Diego Gracia, Voluntad de comprensión. La aventura intelectual de Pedro Laín Entralgo, Madrid, Editorial Triacastela, 2010, p. 554. 
reprochable en su biografía, puede continuar siendo una figura política e intelectual de primer orden en la transición que se avecina.

\section{3. ¿DESCARGO O (AUTO) JUSTIFICACIÓN?}

La palabra clave, por tanto, para entender la intención última de Descargo de conciencia no es confesión ni palinodia sino un término que utiliza el propio Laín:

...la actividad de recordar tiene sirtes y riesgos: la sirte y el riesgo de exagerar la complacencia y el dolor recordados o, por el lado contrario, de quitar hierro, con un subyacente propósito de autojustificación, a lo que suscita el arrepentimiento o el remordimiento ${ }^{33}$.

Voluntaria o involuntariamente, Laín Entralgo ha caído en Descargo de conciencia en el riesgo que él mismo expone en la actividad de recordar, porque ni el examen de conciencia, ni la contrición, ni la confesión, sean públicos o privados, necesitan tantas (auto)justificaciones como las que él hace en su autobiografía, de manera que estas se convierten en vertebradoras del sentido de la misma.

Para cada acción reprobable que recuerda (las hay en toda biografía), Laín imagina un reproche del lector, normalmente en forma de pregunta retórica, con cuya respuesta, en forma de racionalización, pretende, por un lado, desactivar los prejuicios con los que aquel se aproxima a su obra, y por otro explicar los motivos de su actitud (es decir, justificarla). En general, las razones por las que explica la determinación del acto concreto son poco convincentes y admiten claras objeciones, como cuando, por dignidad o por ética, tendría que haber denunciado la situación del Instituto Psiquiátrico Provincial valenciano, que no reunía las condiciones mínimas para que se desarrollara allí una labor médica digna. Como no denunció aquello, inmediatamente aparece la endeble excusa: "Pero frente a una Diputación gobernada por el chabacano caciquismo del partido blasquista, ¿qué hubiera supuesto por aquellos meses la voz de los tres

33 Pedro Laín Entralgo, Hacia la recta final (Revisión de una vida intelectual), Barcelona, Círculo de Lectores, 1990, p. 20. 
únicos médicos verdaderamente dispuestos a levantarla en pro de tal causa, López Ibor, Marco Merenciano y yo?" 34 . Poco convincente es también la justificación que hace de su asistencia al acto "religioso-teatral" de ingreso en la Falange de Eugenio D’Ors, que atribuye a su temperamento, que no sabe resistir el impulso al juego o a la broma ${ }^{35}$. Es tan poco satisfactoria que inmediatamente después el actor de la epicrisis la considera una "cómoda evasiva". La excusa para su permanencia en la cátedra a raíz de las expulsiones de Aranguren, Tierno Galván y García Calvo, es tan peregrina, incluso para él mismo, que, antes de darla, ańade "créaseme o no se me crea..."36.

Sin embargo, las expectativas de la mayoría de los lectores de Descargo de conciencia se relacionan con los aspectos más polémicos de la trayectoria política y pública de Laín Entralgo, como sus escritos de ideología falangista, la defensa del nazismo, su pasividad ante las durísimas represiones del régimen franquista y su connivencia con él. Y para estos "errores" también ha encontrado justificaciones, que fundamenta principalmente en tres pilares: el desconocimiento o ignorancia de lo que sucedía, su ingenuidad o bonhomía y el recurso a la culpa colectiva.

Por lo que se refiere al desconocimiento de lo que estaba ocurriendo, es uno de los descargos que utiliza para razonar su adhesión a las potencias del Eje. Laín expone que hasta 1945 no conoció el exterminio judío ni la existencia de los campos de concentración, aunque visitó Alemania varias veces y conversó con amigos antinazis. Como no puede dejar de reconocer que habría que estar ciego y sordo para no ver el antisemitismo nazi, habla de "íntima repugnancia" ante las actitudes intolerantes, presumiendo de haber ayudado a un anciano judío a cruzar la calle ante la mirada atónita de los arios y de no haber publicado su libro Medicina $e$ historia en alemán por negarse a suprimir los nombres de los judíos Bergson y Scheler. Como en tantas ocasiones, lanza una pregunta retórica que se viene haciendo, según él, desde 1945: “¿Cómo he podido estar al lado de un régimen político que, aun sin yo saberlo, estaba cometiendo tan atroces delitos?" 37 .

34 Pedro Laín Entralgo, Descargo de conciencia, p. 134.

35 Ibidem, p. 217.

36 Ibidem, p. 430.

37 Ibidem, p. 298. 
El que parece su dolor más íntimo, el de su pasividad ante las atrocidades e injusticias de los nacionales durante la guerra y la posguerra, también es justificado por el desconocimiento. "Pero en mi defensa quiero decirte esto: yo, te lo juro, no sabía entonces que la represión de que me hablas hubiese sido tan cruel como realmente fue" 38 . Sin embargo, unas páginas antes ha contado detalladamente su viaje a Sevilla para enterarse del asesinato de su suegro por los nacionales, y también ha narrado un episodio ocurrido pocos días después de su inscripción en Falange (agosto o septiembre de 1936). Se trata de su presencia en el fusilamiento de un condenado a muerte por delito de rebelión, lo que le causa una conmoción tan intensa que después corre a una iglesia y cae en una profunda y acongojada meditación religiosa. En estas reflexiones sobre el fusilamiento vuelve a cuestionarse su adhesión a una causa que mataba sin piedad a indefensos y justifica: "aún no sabía yo cómo y hasta qué punto"39, y eso que acababa de presenciar una ejecución.

El desconocimiento de lo que hacían los de su bando no se sostiene cuando presta este juramento, que intenta cerrar la cuadratura del círculo:

Porque al lado de los criminales que en la retaguardia "roja" o en la retaguardia "nacional" hicieron lo que hicieron, por mi honor puedo jurar que nunca estuve, como no fuese por modo topográfico, aun cuando políticamente yo perteneciera a uno de los bandos de la contienda $a^{40}$.

¿No estuvo al lado de los criminales, aunque pertenecía políticamente a uno de sus bandos? Anteriormente había expuesto una contradicción parecida: después de enterarse en Sevilla del asesinato de su suegro, vuelve a Pamplona, consternado y "más y más obligado a pensar que sólo externa y ocasionalmente -aunque tal ocasión fuera, ahí es nada, una guerra civil a muerte- podía estar al lado de muchos junto a los cuales yo, mirado desde fuera, bélica y políticamente estaba" ${ }^{41}$. ¿Qué significa este galimatías? ¿Qué quiere decir que una persona que perte-

38 Ibidem, p. 220.

39 Ibidem, p. 184.

40 Ibidem, p. 298.

41 Ibidem, p. 187. 
nece bélica y politicamente a un bando sólo está al lado de los asesinos externa y ocasionalmente?

Asimismo, todo el libro está recorrido por una justificación más sutil pero continuamente mencionada: la insistencia en su ingenuidad, sobre todo con respecto a la utopía de la continuamente citada "asunción unitaria y superadora" o "voluntad asuntiva y superadora". Los sintagmas aparecen definidos como "la decisión de integrar a todos los españoles de buena voluntad en una España fiel a sí misma y al nivel de nuestro tiempo" ${ }^{2}$ o "la incorporación leal de los vencidos, de aquellos vencidos en quienes la buena voluntad era cosa cierta o probable, a la España subsiguiente a la victoria" ${ }^{43}$. En los primeros capítulos habla de un "sueño" y "una ilusión adolescentes". Sin embargo, a partir de 1939, aparece el desengaño, pues la España oficial de Franco había roto su esperanza en la patria que la Falange originaria prometió. De esta manera habla de "fracaso" y de "quiebra de mis sucesivas esperanzas como falangista asuntivo y superador y pluralista por representación" "44. Esta desilusión le sirve como justificación para no denunciar públicamente lo que ha visto y ve y para refugiarse en su trabajo intelectual. Al ver que su aventura política no conduce a ninguna parte, cae en la apática procrastinación ${ }^{45}$. Mientras tanto, continúa ocupando cargos relevantes en ese régimen que, al parecer, tanto le desilusiona. De nuevo, la debilidad del argumento para defender su opción por el silencio queda patente. Con los abundantes descargos y los reducidos cargos, Laín Entralgo utiliza su relato para crear un personaje con buenas intenciones, utópico, ingenuo, con una gran "vocación de amigo" y defensor de las causas justas, incluso cuando eran las del bando enemigo.

En definitiva, Laín ha utilizado su autobiografía para vincular al lector por vías emocionales e intentar convencerlo de que su bonhomía ha sido

42 Ibidem, p. 194.

43 Ibidem, p. 266.

44 Ibidem, p. 321.

45 Ibídem, p. 301. La palabra aparece definida en el diccionario de la RAE como "acción de diferir, de aplazar". Se trata de uno de los tantos vocablos de uso arcaizante y ampuloso que confieren al texto un estilo excesivamente grave y envarado. Otros ejemplos: potísima (p.98), responsiva (p. 111), roborante (p. 142), oblativa (p. 180), elpidica (443), agapética (p. 444)... 
la rectora de todos sus actos. Sin embargo, a pesar de estos intentos, él mismo es consciente de la posibilidad de no haber anulado los prejuicios del lector pues al terminar el libro se pregunta: "Moralmente, de algo me sirve a mí el hecho de publicar, aunque con tanto retraso, este viejo descargo de conciencia. ¿Les servirá también a quienes ahora lo lean?" 46. Como se verá más adelante, a juzgar por la reacción de algunos lectores, la respuesta es negativa.

Por lo que se refiere a la culpa colectiva, Laín se encarga de dejar claro que él está realizando una palinodia que tendría que ser colectiva, como colectivo fue el pecado que está confesando. Esta idea recorre todo el libro pero es en el epílogo cuando le dedica mayor extensión y habla de un nostra culpa que debería ser entonado, incluso por la Iglesia española, que, según él, no ha dicho todavía lo suficiente "respecto de los graves e indudables desafueros cometidos" en la zona nacional ${ }^{47}$, ha mantenido un silencio total ante la represión política de los vencedores y no ha tenido una suficiente actitud crítica frente a las privaciones materiales de la posguerra $^{48}$. Parece como si además de un ajuste de cuentas consigo mismo, Laín estuviera ajustándolas con algunos más, o que quisiera extender su culpa, por ejemplo, a todos los que formaron parte del bando nacional, pues son constantes los reproches hacia ellos ${ }^{49}$ por no haber denunciado lo que tampoco denunció él. En este sentido se comprendería también el comentario ante el pecado por omisión (pudo haber hecho más de lo que hizo) que le confiesa al juez: "Más que yo hicieron algunos; menos que yo, muchos" 50 . A lo que habría que ańadir que el asunto en un libro autobiográfico que él publica voluntariamente no es lo que hicieron los otros, sino lo que hizo (o no hizo) él. Asimismo, al hacerlos a todos cul-

46 Ibidem, p. 429.

47 Ibidem, p. 427.

48 Ibidem, p. 277.

49 "Uno y otro [...] comenzaron a enseñarme en vivo algo que más tarde tantas y tantas veces había de ver yo: la incapacidad de nuestra derecha para la denuncia de cualquier fechoría cometida en aras del que ella considera "su orden»" (p. 187); "Sí, pero entre los otros siempre hubo alguna voz denunciadora. La voz que ni durante la guerra civil, ni después de ella, ha sonado públicamente en las filas "nacionales»" (p. 187, nota 2); “'¡por qué esta dura, cerrada resistencia de la derecha española al examen crítico de su conducta colectiva, sea ésta la de hoy o la de ayer?” (p. 269).

50 Ibidem, p. 269. 
pables, él no siente esa culpa o, cuando menos, la diluye, pues, como el psiquiatra Castilla del Pino expone, para sentirse culpable es preciso "que los demás -los otros- sean «inocentes», cuando menos de la culpa de que me reprocho y se me reprocha" 51 .

En resumen: Laín Entralgo solo se confesó públicamente cuando tuvo otras razones que el mero descargo para hacerlo. Su compulsión justificativa se explica porque sabía que, una vez acabado el franquismo, muchos españoles iban a pedirle cuentas de su actitud durante la guerra y de su connivencia con el régimen, más cuando él tenía intención de adaptarse al sistema democrático. De ahí que se apresurara a hacer la confesión pública en la que en algunas ocasiones (pocas) se percibe remordimiento y dolor, pero la actitud que prevalece es la defensiva con escasa autocrítica. El arrepentimiento del que habla es mínimo comparado con el afán de justificación y depuración de su pasado.

\section{LAS EPICRISIS COMO ESTRATEGIAS DE PERSUASIÓN}

Gran conocedor de la retórica clásica, Laín utilizó varios de sus recursos, con fines esencialmente persuasivos, en Descargo de conciencia. El más original e interesante son las epicrisis finales de cada capítulo, cuyo significado explica en una nota a pie de página ${ }^{52}$. La palabra, proveniente del griego, se aplica "al juicio razonado que el médico establece acerca de lo que en su realidad ha sido la dolencia de un enfermo, bien cuando ésta ya ha pasado, bien cuando ha transcurrido una etapa importante de ella”. Consecuente con esta definición, Laín utiliza las suyas para presentar al lector el juicio razonado de lo que fue y lo que hizo en los periodos que relata en los capítulos que las preceden. Para este juicio, el autor escinde el yo en tres personajes: el que antaño hizo lo que hizo (el actor de una pieza teatral), el que también antaño desde el interior decidía, contemplaba e interpretaba su propia conducta (el autor de la pieza) y el que, desde el presente, mira y juzga a los dos anteriores (el juez). Entre estos tres yoes se establece una dramatización que recoge las culpas, los arrepentimientos, los reproches y las justificaciones que Laín Entralgo quiere

51 Carlos Castilla del Pino, La culpa, Madrid, Alianza Editorial, 1973, p. 131.

52 Pedro Laín Entralgo, Descargo de conciencia, p. 80. 
presentar al lector. Sin embargo, también a lo largo de los capítulos Laín va diseminando todo lo que reúne en las epicrisis, de manera que estas son redundantes en muchas ocasiones, por lo que su función parece la de dejarle al lector todo reflexionado y organizado, sobre todo los reproches que pueda hacerle al autor.

Con esta forma de discurso Laín imita el modelo judicial al constituir un tribunal imaginario delante del cual se descarga el inculpado ante un juez que tiene que escucharlo para después dictar sentencia. Esta puesta en escena, afirma Gisèle Mathieu-Castellani ${ }^{53}$, es utilizada desde las Confesiones de San Agustín, ya que tiene la ventaja de mostrar la multiplicidad de voces que hablan en la autobiografía y sus íntimas disonancias. De esta forma, Laín se sitúa en posición de culpable, de acusador, de acusado, de abogado y de juez y se va deslizando de un papel a otro, presentándose ante el Tribunal como acusado acusador y fluctuando entre la declaración de inocencia y la confesión pública de culpabilidad.

Es en las epicrisis donde aparecen las justificaciones más importantes de la obra, como la ya mencionada del capítulo VI, en la que el autor explica al juez que no hizo antes el descargo de conciencia porque no se sentía moralmente culpable; o la del capítulo IV, el segundo de los dedicados a la guerra civil, en la que jura que desconoce que la represión nacional haya sido tan importante: "Pero en mi defensa quiero decirte esto: yo, te lo juro, no sabía entonces que la represión de que me hablas hubiese sido tan cruel como realmente fue" 54 . También en ellas es donde se confiesa de manera que parece más sincera: "Por omisión pequé, lo reconozco sin reservas" 55 , "Con dolor me arrepiento de ella" 56 . Para entender la importancia de las epicrisis como recurso retórico para influir en el lector, es muy significativa la intervención del juez en la del capítulo $\mathrm{V}$, el último dedicado a la guerra civil, en el que aquel sentencia de esta manera la actuación de Laín durante la contienda: "No te condeno, pero tampoco te absuelvo. [...] Admito, por supuesto, la verdad de lo que en tu

53 Gisèle Mathieu-Castellani, La scéne judiciaire de l'autobiographie, París, PUF Écriture, 1996, p. 220.

54 Pedro Laín Entralgo, Descargo de conciencia, p. 220.

55 Ibidem, p. 255

56 Ibidem, p. 351. 
favor alegas, y no pretendo negar cierto valor a varias de tus acciones" 57 .

Para exponer tanto las argumentaciones como las refutaciones, Laín Entralgo usa en muchas ocasiones uno de los recursos de la retórica clásica: el de la partición, que, según Mortara Garavelli ${ }^{58}$, consiste en enumerar los puntos que han de tratarse. Como los ejemplos son muy numerosos, se ejemplificarán con dos de los que aparecen en las epicrisis, aunque en los capítulos el recurso es utilizado frecuentemente. En la primera numera y explica los seis tipos de entes biográficos: 1. Los que van siendo de hecho lo que en el mundo tenían que ser; 2. Quienes son en su vida lo que se sienten llamados a ser, y sólo eso; 3. Aquellos cuyo motor constante es su propia veleidad, su voluntad antojadiza; 4. Los que en su vida cambian y cambian porque saben beneficiarse de los golpes de su fortuna; 5. Los que se ven forzados a ser lo que de ningún modo quisieran ser; 6 . Aquellos en quienes late una vocación real pero excesivamente genérica, opera una voluntad no demasiado firme y por azar van hallándose en situaciones que sólo de un modo parcial les permiten cumplir alguna de las determinaciones específicas de la vocación ${ }^{59}$. En la del capítulo VI, el juez declara: "Por mi parte, yo entiendo que cuando en materia tocante a la vida pública uno ha errado de tan grave modo, la integridad de su deber ante esa vida comprende hasta cuatro puntos: palinodia, abstención, denuncia moral y trabajo vocacional. Más explícitamente..."60.

La escenificación judicial que tiene lugar en las epicrisis enlaza, además, con las dimensiones éticas de la escritura autobiográfica de las que habla Loureiro, cuando se entiende aquella como un acto que responde y se dirige al otro. La relación de deuda entre el yo y el otro (Loureiro apela a la filosofía de Levinas) se manifiesta en la autobiografía no sólo en los modos de construcción de la identidad sino en los términos que los autobiógrafos usan para dirigirse a los destinatarios, normalmente a través del apóstrofe, aunque sin olvidar la prosopopeya ${ }^{61}$, pues esta última adquiere

57 Ibidem, p. 253.

58 Bice Mortara Garavelli, Manual de retórica, Madrid, Cátedra, 1988, p. 81.

59 Descargo de conciencia, pp. 82-83.

60 Ibidem, p. 352.

61 Según Loureiro, en su caracterización moderna la prosopopeya ha perdido aspectos de la retórica clásica que se adaptan perfectamente a su uso en la autobiografía, y en concreto, a Descargo de conciencia, ya que, en palabras de Quintiliano, la prosopope- 
gran relevancia en la escritura autobiográfica al dar forma a la estructura conflictiva y dialógica del yo; dicho de otro modo, es capaz de representar la configuración adversarial de la conciencia (ese esencial dirigirse al otro). Así se entienden las epicrisis de Laín Entralgo como un discurso dirigido al otro: él mismo en diferentes yoes y etapas y, a la vez, el lector. En Descargo de conciencia la orientación hacia el otro es evidente en dos elementos de las epicrisis: en primer lugar, en la presencia de destinatarios textuales de forma explícita; y en segundo, en la frecuente utilización del apóstrofe.

Por lo que a los destinatarios del texto se refiere son los dos yoes del pasado (actor y autor) a los que se dirige el juez, que, según Laín, es el yo del momento de la escritura pero que podría representar también al lector. Los tres personajes dramatizan un juicio en el que los dos primeros presentan sus descargos y el juez sirve para, en primer lugar, dar voz a la conciencia del sujeto enunciador y a los reproches del lector y finalmente para sentenciar el juicio. En realidad, la escenificación está construida para interpelar al lector y que este emita el veredicto.

En cuanto a la utilización del apóstrofe, es este el recurso que pone de relieve a los destinatarios del texto; de ahí que aparezca con frecuencia en las intervenciones del juez: "Soy, amigo autor, el yo que con el paso del tiempo tú (...) has venido a dar" ${ }^{62}$; "Tú, actor, te limitaste a ejecutar como mejor pudiste el papel que para ti fue inventando tu autor. Tú, autor, no pasaste de responder..." ${ }^{3}$; "No como juez sino como persona voy a hablaros; muy en primer término, a ti, autor" ${ }^{64}$. También el actor y el autor las utilizan en sus respuestas: "Ante ti, mi autor, tengo que dar cuenta de mi manera de representar el papel que entonces me entregaste. Ante ti, mi juez, debo soportar que desde tu olímpica altura vital -¡cuarenta años más que yo, no lo olvides!- censures lo que entonces yo hice" ${ }^{65}$.

ya sirve para mostrar los pensamientos internos de los adversarios como si estuvieran hablándose a sí mismos o para presentar conversaciones en las que podemos poner palabras de consejo, reproche, queja, alabanza o compasión en las bocas de las personas apropiadas. Véase Ángel Loureiro, op. cit., p. 22.

62 Pedro Laín Entralgo, Descargo de conciencia, p. 111.

63 Ibidem, p. 172.

64 Ibidem, p. 218.

65 Ibidem, p. 252. 
Hasta el epílogo en Descargo de conciencia es usado con fines persuasivos, pues Laín lo utiliza para el llamado "movimiento de afectos"66; en este caso concreto el afecto de la compasión, de manera que Laín inserta en casi nueve páginas la carta ya mencionada, en la que se ven las muestras más evidentes de dolor. En "este viejo descargo de conciencia" habla de confesión, de problema de conciencia, del nostra culpa y del pecado histórico, de forma que se convierte en una especie de recapitulación de todo lo que ha ido exponiendo a lo largo del libro. Tan importante es para Laín el efecto de la misiva en los lectores que se plantea la siguiente pregunta: "Moralmente, de algo me sirve a mí el hecho de publicar, aunque con tanto retraso, este viejo descargo de conciencia. ¿Les servirá también a quienes ahora lo lean?" ${ }^{7}$.

En Descargo de conciencia, el lector no es interpelado como simple espectador, ni como testigo ${ }^{68}$ o cómplice literario ${ }^{69}$, sino que, con la escisión del autor no en dos sino en tres yoes, la estrategia de adelantarse a los reproches y censuras que se le pudieran hacer y sus numerosas justificaciones, explicaciones y confesiones íntimas, Laín lo apela como confidente de la confesión, buscando su comprensión, indulgencia y por último su absolución, ya que, por un lado, la confesión es inútil si no es recibida por lectores benevolentes, y por otro, en el fondo de toda confesión hay un deseo de ser absuelto.

\section{Diferentes lecturas de la obra}

Esa fue la intención de Laín, pero ¡cómo recibieron los lectores la obra? Es indudable que la obra suscitó su interés pues a los seis meses de su publicación hubo de reimprimirse y durante todos estos meses estuvo en las listas de los diez libros de ensayo más vendidos. Laín habló en el prólogo a la primera edición de "quienes con buena voluntad lleguen a leerlo", pero, como él bien sabía, otra cosa diferente es la pragmática del texto y

66 Bice Mortara Garavelli, op. cit., p. 116.

67 Pedro Laín Entralgo, Descargo de conciencia, p. 429.

68 Como ocurre por ejemplo en Pretérito imperfecto de Carlos Castilla del Pino.

69 Como hace José Manuel Caballero Bonald en los dos volúmenes de su obra autobiográfica: Tiempo de guerras perdidas y La costumbre de vivir. 
la interpretación que el lector hizo de su obra, de modo que en el prólogo a la edición de 1989 se refiere a los "lectores de alma limpia"70, aclarando a continuación que no todos lo son. A esas alturas, el libro ya había dado lugar a muchas reacciones e interpretaciones. Rastreando los periódicos de la época (el recién estrenado El País, $A B C$ y La Vanguardia), aparece la noticia de la presentación del libro en Madrid y varias reseñas sobre la autobiografía. La presentación del libro, en forma de coloquio, tuvo que ser polémica a juzgar por los comentarios que de ella realizan tanto los periodistas como algunos asistentes y el mismo Laín ${ }^{71}$.

A partir de la publicación del descargo, los artículos y reseñas sobre él se multiplican ${ }^{72}$. Todas ellas son encomiásticas y defienden el acto de valentía que ha realizado Laín, preguntándose algunos, como López Aranguren, de qué tiene que descargarse la conciencia el autor.

Sin embargo, estas adhesiones contrastan con la publicación en 1978 de la novela de Juan Marsé La muchacha de las bragas de oro, premio Planeta de aquel año, donde un escritor falangista, Luys Forest, redacta sus memorias, que revisa una y otra vez y en las que no duda en mentir y en rehacer interesadamente la verdad si es necesario. La cita de Henry James que encabeza el libro ("Sus viejos padres no podían hacer gran cosa con el porvenir y han hecho lo que han podido con el pasado"), las dos primeras líneas de la novela ("Hay cosas que uno debe apresurarse a contar antes de que nadie le pregunte”) y el evidente parecido entre algunos aspectos biográficos de Luys Forest (convalece en un hospital de Pamplona, pasa en Burgos la guerra, en Barcelona organiza los servicios de Propaganda, dirige la colección "Crónicas” de Ediciones Jerarquía ${ }^{73}$ ) y los de Laín En-

70 Pedro Laín Entralgo, Descargo de conciencia, p. 23.

71 Jacinto López Gorgé, "República de las letras", $A B C, 29-05-1976$, p. 67; Carmen Castro, "Peregrino espectáculo. Libros incómodos", La Vanguardia, 06-06-1976, p. 15; Pedro Laín Entralgo, "Cartas al director", con el título "Uno y su propio pasado", $A B C, 27-05-1976$, p. 6.

72 Entre ellas: Miguel Ángel Molinero, "Descargo de conciencia de Pedro Laín Entralgo”, ABC, Blanco y Negro, 26-06-1976, p. 66; José Luis López Aranguren, "La trayectoria de Laín. Conciencia, búsqueda de identidad y vocación", La Vanguardia, 30-06-1976, p. 15; Julián Marías, "La conciencia de Pedro Laín", La Vanguardia, 25-06-1976, p.19; y "Los supuestos”, El Pais, 29-06-1976: http://elpais.com/diario/1976/06/29/espana/204847226_850215.html (consultado el 21-10-2015).

73 Es el título de la revista que publicaron en Pamplona en la guerra civil, entre otros, 
tralgo no dejan dudas sobre la inspiración que a Marsé le supuso la lectura de Descargo de conciencia ${ }^{74}$.

Asimismo, un año antes, en 1977, Carlos Castilla del Pino había publicado una obra en la que también arremete contra Laín Entralgo y su "descargo". Discurso de Onofre muestra en alguno de sus párrafos irritación por la publicación de las memorias de Laín. Castilla del Pino utiliza el tópico del manuscrito encontrado para editar los escritos de Onofre Gil, nombre falso de un médico psiquiatra que se suicidó y dejó unos papeles, entre ellos el discurso, que casualmente acaban en manos del autor $^{75}$. El psiquiatra gaditano habla de "los que por afortunado azar fueron educados entre hijos de san Ignacio, en el Burjasot college"76, es decir, de López Ibor, Marco Merenciano y Laín Entralgo. Y añade: "Y qué bien mataron o dejaron matar o lo incitaron, sin que les enturbiase el ánimo opuesta instancia capaz de sumirles en torturantes escrúpulos que hacen la tragedia de humanos tridimensionales"77. Y en una alusión evidente a Laín Entralgo aparece la reprobación:

Hay incluso algunos que en reiterada palinodia se autolamentan de aquellas aplicaciones de otros tiempos, no sé bien si por excesivamente tímidas o por ineficaces. Se trata de gente en extremo dubitativa, sin duda fruto de la senectud, porque es claro que por aquellos tiempos no dudaron. [...] Pasado el tiempo, [...] viene la hora de la conciencia descargable e intentan dolorosamente un descargo imposible, y por tanto incompleto, que les convierte en concertistas virtuosos de contumaz palinodia. Sí, pero no así, que fue demasiado, reza la fór-

Pedro Laín y Fermín Yzurdiaga, con el subtítulo: "Revista Negra de la Falange".

74 En un artículo titulado "Cadáver exquisito", recogido en Ronda Marsé (p. 309), Carlos Barral, que conocía muy bien a Marsé, explica cómo el protagonista de la novela tiene rasgos de algunos personajes públicos (él mismo, Luys Santamarina, Eugenio D’Ors...), pero sobre todo de Laín Entralgo.

75 En la nota 138 de Pretérito imperfecto, Carlos Castilla reconoce que se inspiró en un psiquiatra al que conoció en Madrid, Antonio Rosado, para encarnar la figura y la muerte de Onofre Gil. Por otro lado, los elementos autobiográficos de Discurso de Onofre son varios, como lo demuestran los episodios que en esta novela se narran y que luego han sido plasmados en Pretérito Imperfecto o en Casa del olivo.

76 Carlos Castilla del Pino, Discurso de Onofre, Barcelona, Península, 1977, p. 28.

77 Ibidem, p. 29. 
mula y viene el strido: arrepentido me he, ;mea culpa! ${ }^{18}$.

Las adhesiones mayoritarias a Descargo de conciencia se explican por el espíritu de conciliación que predominó en el momento de la publicación del libro, la recién inaugurada Transición. Sin embargo, pasados los ańos, cuando alrededor del cambio de milenio comienza a cuestionarse la Transición como etapa modélica y surgen los llamados nietos de la guerra, que hacen una reivindicación pública de las víctimas de la guerra y del franquismo, resurgen las interpretaciones del libro de una manera no tan propicia a la intención del autor, como las que hicieron en 2006 Santos Juliá e Isaac Rosa. El primero se refiere a Descargo de conciencia como "un libro fundamental para conocer quién era su autor cuando lo publicó en 1976 pero engañoso para tener una idea aproximada de lo que había sido treinta años antes"79. Isaac Rosa se refiere al libro en términos mucho más duros:

Supongo que muchos lectores del Descargo [...] tendrán cautela a la hora de dar crédito al relato que de su vida hace Laín. Su trayectoria en guerra y posguerra está narrado (sic) con remilgos y piruetas para disculpar su destacado papel en el falangismo triunfante. Se autorretrata como un cándido joven, "falangista sin vocación" víctima del "sarampión del momento" y de una "adolescente ilusión"; un "utopista de la Guerra Civil" que toma las decisiones y asume los compromisos casi por casualidad, desde la "ingenuidad y el desconocimiento", que está en el sitio adecuado y a la hora precisa sin intención. Un Forrest Gump de la guerra espańola, inocente, bienintencionado, que acude al congreso del partido nazi en Alemania en actitud más turística que militante ${ }^{80}$.

A esta polémica se suman, defendiendo a Laín, José Lázaro ${ }^{81}$ y Vidal Be-

78 Ibidem, pp. 37-38.

79 Santos Juliá, "Trampas de la memoria”, El País, 14-10-06: http://elpais.com/diario/2006/10/14/babelia/1160782750_850215.html (consultado el 12-10-2015).

80 Isaac Rosa, "Los espinazos curvos de la dictadura", El País, 14-10-2006: http://elpais.com/diario/2006/10/14/babelia/1160782754_850215.html (consultado el 1210-2015).

81 José Lázaro, "Pedir perdón, aunque sea póstumo", El País. Babelia, 09-12-2006: http://elpais.com/diario/2006/12/09/babelia/1165625426_850215.html (consultado el 12-10-2015). 
neyto ${ }^{82}$. Además, en 2014, Gregorio Morán en El cura y los mandarines escribe nueve páginas muy críticas con la figura y la autobiografía de Laín Entralgo. Sobre Descargo de conciencia sentencia que su importancia radica en que sentó las bases de una manera de mirar hacia el pasado, manipulándolo y mostrando la siguiente fórmula: "aunque yo estaba presente, en el fondo me repugnaba. ¡Qué otra cosa podría hacer que resignarme ante aquellos espectáculos que me desagradaban!" ${ }^{83}$. Esta forma de juzgar su pasado, se convertirá, según Morán, en modelo para buena parte de los padres de la Transición.

Todo lo anterior muestra el contraste entre las diferentes lecturas del mismo texto. Por un lado, la que realizan los que, de una manera u otra, tuvieron relación con Pedro Laín y, por tanto, implicaciones afectivas, y se han convertido en sus más auténticos valedores, y la de los autores que glosaron el libro en el momento de su aparición y que consideraron oportuno, en aras de la convivencia pacífica, no polemizar en torno a la figura de Laín y sus cambios ideológicos. Por otro, la lectura de una nueva generación que ha leído el libro en un momento de reivindicación de la memoria histórica y que ven en el autor (ya sin implicaciones afectivas) un ejemplo de oportunismo y en su obra no poco de auto-indulgencia. En todo caso, es indiscutible que las implicaciones pragmáticas de Descargo de conciencia perduran hasta hoy mismo.

82 José Vidal Beneyto, "No nos equivoquemos de cadáveres", El País, 29-12-2006, p. 14.

83 Gregorio Morán, El cura y los mandarines. Historia no oficial del Bosque de los Letrados. Cultura y política en España (1962-1996), Madrid, Akal, 2014, p. 594. 